\title{
A Three-Stage Mechanistic Model for Solidification Cracking During Welding of Steel
}

\author{
L. AUCOTT, D. HUANG, H.B. DONG, S.W. WEN, J. MARSDEN, A. RACK, \\ and A.C.F. COCKS
}

\begin{abstract}
A three-stage mechanistic model for solidification cracking during TIG welding of steel is proposed from in situ synchrotron X-ray imaging of solidification cracking and subsequent analysis of fracture surfaces. Stage 1-Nucleation of inter-granular hot cracks: cracks nucleate inter-granularly in sub-surface where maximum volumetric strain is localized and volume fraction of liquid is less than 0.1 ; the crack nuclei occur at solute-enriched liquid pockets which remain trapped in increasingly impermeable semi-solid skeleton. Stage 2-Coalescence of cracks via inter-granular fracture: as the applied strain increases, cracks coalesce through inter-granular fracture; the coalescence path is preferential to the direction of the heat source and propagates through the grain boundaries to solidifying dendrites. Stage 3-Propagation through inter-dendritic hot tearing: inter-dendritic hot tearing occurs along the boundaries between solidifying columnar dendrites with higher liquid fraction. It is recommended that future solidification cracking criterion shall be based on the application of multiphase mechanics and fracture mechanics to the failure of semi-solid materials.
\end{abstract}

https://doi.org/10.1007/s11661-018-4529-z

(C) The Minerals, Metals \& Materials Society and ASM International 2018

\section{INTRODUCTION}

Multiple mechanisms for solidification cracking during metal manufacturing processes such as casting, welding, and more recently additive manufacturing have been proposed. Sigworth ${ }^{[1]}$ and Eskin et al. ${ }^{[2]}$ reviewed the research field in 1996 and 2004. Some of the first studies of importance include Pellini's "strain theory of hot tears" proposed in 1952, ${ }^{[3]}$ Humphrey and Jennings "shrinkage-brittleness theory" in $1948,{ }^{[4]}$ and Borland's "generalized theory" in $1960 .^{[5]}$ The generalized theory combined and modified the "strain" and "shrinkage-brittleness" theories. All these early solidification cracking theories are in the agreement that solidification cracking occurs with thermally mechanically induced strain at the late stages of solidification when the fraction of liquid is less than 0.1 .

In 1976, Feurer ${ }^{[6]}$ studied liquid presence between grains and argued that a solidification crack will

L. AUCOTT is with AWE Plc, Aldermaston, Reading, RG7 4PR, UK. D. HUANG and A.C.F. COCKS are with the Department of Engineering, University of Oxford, Oxford, OX1 3PJ, UK. H.B. DONG and S.W. WEN are with the Department of Engineering, University of Leicester, Leicester, LE1 7RH, UK. Contact e-mail: h.dong@le.ac.uk J. MARSDEN is with the Tata Steel, Swinden Technology Centre, Rotherham, S60 3AR, UK. A. RACK is with the European Synchrotron Radiation Facility, 38043 Grenoble Cedex 9, France.

Manuscript submitted September 27, 2017.

Article published online March 2, 2018 nucleate as a pore if the liquid is no longer able to fill the inter-granular openings. However, this study only considered the contribution of solidification shrinkage. In 1988, Guven and Hunt ${ }^{[7]}$ emphasized the role of tensile stresses in the formation of solidification cracks. In 1999, Rappaz et al. ${ }^{[8]}$ proposed a RDG model by extending Feurer approach ${ }^{[6]}$ to include feeding associated with tensile deformation of the solidified material. The RDG model was the first hot tearing model with a physically sound basis. However, phase changes and the grain boundary, where cracking occurs, were not taken into account. In 2003, Campbell ${ }^{[9]}$ emphasized that solidification cracking criteria generally neglect the importance of thermo-mechanical aspects and simply consider the alloy's solidification temperature range: the larger the freezing range, the more susceptible the alloy will be to solidification cracking. In 2015, Kou ${ }^{[10]}$ developed a model focusing on events occurring at the grain boundary, such as: separation of grains from each other, lateral growth of grains toward each other, and liquid feeding between grains.

To date, the potential driving forces for solidification cracking are well-established: solid contraction in a thermal gradient, solidification shrinkage, and a high sensitivity to solute segregation. However, nucleation and propagation mechanisms are inconclusive and hindered by a lack of direct experimental observation to validate the theories proposed. Only recently have experimental observations on solidification cracking started to emerge: first for transparent analogues in 
2001 and 2002 $2^{[11,12]}$ and then aluminum alloys ${ }^{[13-22]}$ from 2006 to 2017. The following crack nucleation sites have been suggested as a result:

1. Liquid film or liquid pool ${ }^{[23]}$;

2. Pore or series of pores ${ }^{[8,19-22,24]}$;

3. Grain boundary located in the place of stress concentration $^{[18,25,26]}$;

4. Inclusions that can be easily separated from the liquid or solid phase $\mathrm{e}^{[9,15-17,27]}$

5. Semi-solid phases with shear-induced dilatancy. ${ }^{[28-30]}$

Cracking criterions proposed to date are generally developed for $\mathrm{Al}$ alloy systems and then retrospectively applied to Fe systems. However, significant differences in solidification sequence and temperature range exist between the two systems. What is now needed is a thorough and systematic study of cracks occurring in solidifying steels with the aim to single out the nature and the critical dimensions of defects or structure features that cause nucleation and propagation of solidification cracks. ${ }^{[31-35]}$ This is particularly important in high-solidification-rate manufacturing processes such as welding and additive manufacturing, as defects occurring during these processes are not covered in current literature. It is also necessary, in our opinion, to acknowledge that different mechanisms of crack propagation are possible during different processing conditions and also at different fractions of solid/liquid evolution.

In a previous study, an in situ synchrotron X-ray imaging experiment ${ }^{[36]}$ was presented to observe and quantify the initiation and growth kinetics of solidification cracking during welding of steel. In the current study, the mechanisms for solidification cracking are elaborated by identifying the thermodynamic state and localized structure features at nucleation sites and the resultant fracture surfaces. The elucidation of these key parameters provides further insight into the nucleation and propagation mechanisms and allows for a threestage mechanistic model for solidification cracking during high-solidification-rate processing of steel to be proposed.

\section{EXPERIMENT}

A strain-based deformation stage was developed for real-time imaging of solidification cracking during welding. A schematic of the experimental setup is illustrated in Figure 1(a). The synchrotron experiments were conducted at the European Synchrotron Radiation Facilities ID19 beamline.

Test samples of $8 \times 8 \times 300 \times 10^{-9} \mathrm{~m}^{3}$ were prepared from EN1A mild steel with a nominal chemistry (wt pct) of $0.15 \mathrm{C}-1 \mathrm{Mn}-0.35 \mathrm{Si}-0.06 \mathrm{P}-0.6 \mathrm{~S}$. To improve X-ray image quality, it is imperative to minimize the path length through the sample. The $8 \times 10^{-3} \mathrm{~m}$ sample thickness was selected as it was the smallest feasible to weld upon. For the welding, a high-solidification-rate tungsten inert gas (TIG) process was used. TIG welding was carried out at $10 \mathrm{~V}$ and $98 \mathrm{~A}$ with a non-consumable tungsten electrode in DC-ve polarity. During welding, weld pool solidification temperature was measured by tungsten-rhenium Type $\mathrm{C}$ thermocouples. The resultant temperature curve was used in conjunction with thermodynamic predictions of the solidification temperature range to give a guide measure of solidification rate at $784 \mathrm{~K} / \mathrm{s}$.

Thermo-calc TCFE7 thermodynamic database was used to predict solidification temperature range and volume fraction of liquid $v s$ temperature through solidification process under both equilibrium and Scheil conditions. Hot ductility tests were carried out on a 3800 Gleeble machine. Eight samples were tested at intervals across the solidification temperature range to determine a stress and reduced area $v s$ temperature curve.

A mean photon energy of $110 \mathrm{keV}$ was used for in situ radiography. A view window of $1872 \times 1000$ pixels was employed with a $10 \times 10^{-5} \mathrm{~m} /$ pixel resolution. The camera continuously recorded images at a rate of 1000 fps to satisfy the temporal demands in observing the solidification cracking in situ. More details about the experimental procedure have been described in our previous publication. ${ }^{[36]}$ In order to enhance the contrast of the cracks by means of X-ray inline phase contrast, a propagation distance of $7.3 \mathrm{~m}$ between sample and detector was realized. ${ }^{[37]}$

All post-processing of the captured image data was performed using the public domain Java image processing program Image J, ${ }^{[38]}$ with the assistance of a simple processing routine detailed in Reference 36. An example of a typical post-processed radiograph is presented in Figure 1(b).

Micro-tomography was carried out post-mortem with a similar experimental configuration to the in situ radiography. The propagation distance was $1.2 \mathrm{~m}$. 1200 projection images were recorded per sample in order to ensure good tomographic reconstruction quality. For 3D image reconstruction, the ESRF in-house software PyHST_2 was used which is based on the filtered-back projection approach. The resultant image stacks were then filtered using a 3D median filter to remove high contrast speckle noise, and then sharpened to enhance the edges using ImageJ. Volume rendering of the stacks and volumetric analysis were carried out in Drishti volume exploration software. An example of the reconstructed crack network is illustrated in Figure 1(c).

Subsequent fracture surfaces were analyzed with a FEI Sirion 200 field emission gun-scanning electron microscope (FEG-SEM). The FEG-SEM also has an incorporated energy dispersive X-ray (EDX) module which is used to quantify localized chemistry and identify specific features triggering nucleation.

\section{RESULTS AND DISCUSSION}

\section{A. Thermodynamic Analysis of Solidification Cracking}

In this section, thermodynamics for solidification crack nucleation and propagation is investigated. Figure 2 illustrates solidification stages, in terms of 


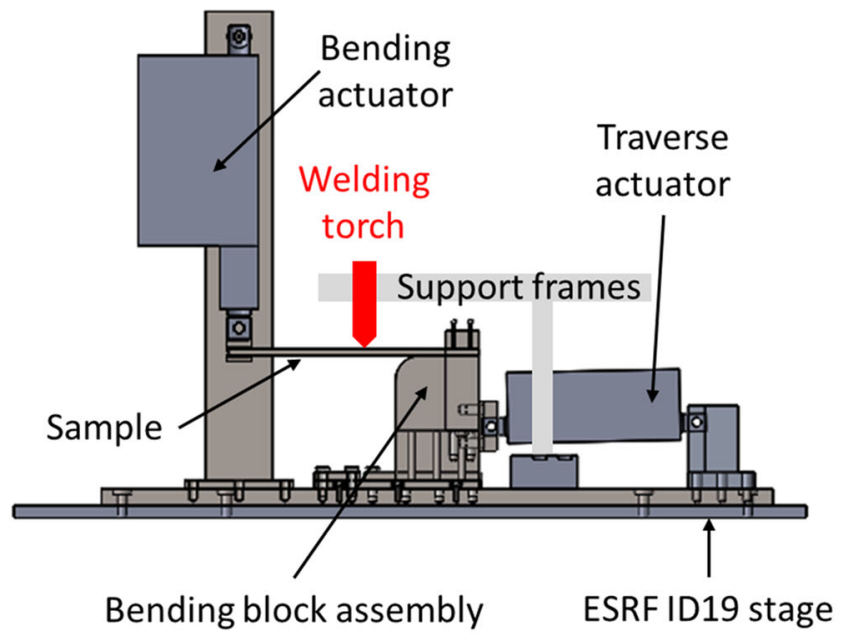

(a)

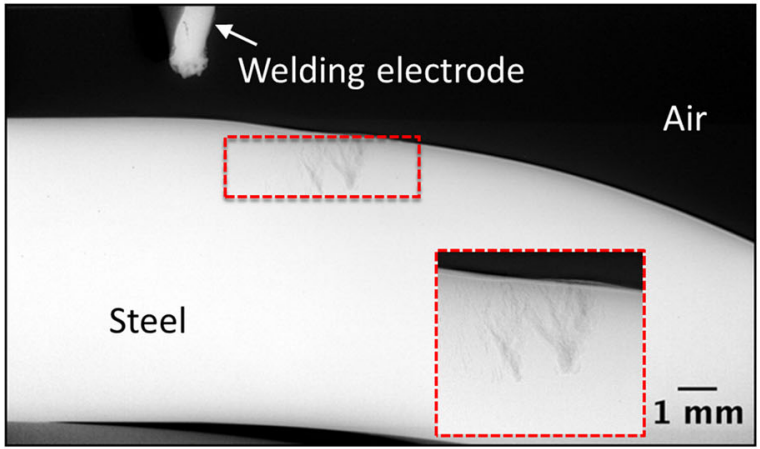

(b)

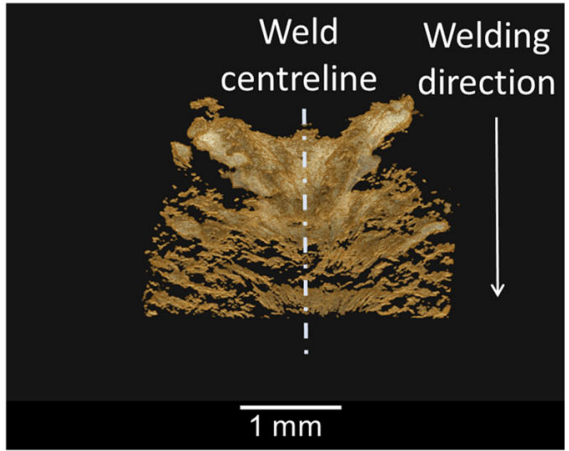

(c)

Fig. 1-Summary of the experimental procedure detailing: $(a)$ a schematic illustration of the strain-based deformation stage used for in situ radiography, (b) a typical in situ radiograph, solidification cracks are clearly distinguishable being darker than the bulk sample in steel, $(c)$ post-mortem $3 \mathrm{D}$ reconstruction of the resultant solidification crack network.

temperature and volume fraction of solid, calculated from Thermo-Calc simulations under equilibrium and non-equilibrium (Scheil) solidification conditions. Santillana et al.$^{[39]}$ described the stages in detail; however, in relation to solidification cracking, only the final stages of solidification (stage $2 \mathrm{~b}$ and 3 ) are applicable. At Stage $2 \mathrm{~b}\left(f_{s} \sim 0.8\right.$ to 0.9$)$, with increasing solid fraction, liquid starts to be isolated in pockets or immobilized by surface tension. During these sub-stages, as liquid is trapped between interlocking dendrites, the free passage for liquid is blocked, transforming continuous liquid films into isolated liquid droplets or pockets. As a result, the strength of the material is very low due to the existence of this non-continuous liquid film between the primary dendrites. If an external stress is applied to the material, then solidification cracking can easily occur in the form of inter-dendritic hot tears. Stage $3\left(f_{s}>0.9\right)$ marks the transition from the dendritic to the grain structure. At this stage, the boundaries of the primary dendrites become invisible on polished sections. A thin liquid film can still be present at the grain boundaries due to the presence of segregated elements in the liquid, lowering the melting point of this film. Solidification cracks formed at this stage are named as "inter-granular hot cracks" to distinguish them from the "inter-dendritic hot tears" formed during stage $2 \mathrm{~b}$. It is important to clarify the difference between the two cracking features at this early stage.

The thermodynamic simulations presented in Figure 2 give a broad spectrum of temperature ranges for solidification cracking. To determine the thermo-mechanical properties more accurately, Gleeble hot ductility tests were performed with the results presented in Figure 3. Based on examination of the hot ductility results, the onset of elongation was first observed on the sample tested at $1410{ }^{\circ} \mathrm{C}$. Therefore, the zero ductility temperature (ZDT) was deduced to lie between $1375^{\circ} \mathrm{C}$ and $1410{ }^{\circ} \mathrm{C}$. Similarly, the zero strength temperature (ZST) was deduced to lie between the points when the brittle fracture surface first appears at $1430{ }^{\circ} \mathrm{C}$ and then becomes molten at $1450{ }^{\circ} \mathrm{C}$. As such, the approximate brittle temperature range (BTR), where $\mathrm{BTR}=$ ZST-ZDT, obtained directly from hot ductility tests is between $20{ }^{\circ} \mathrm{C}$ and $75^{\circ} \mathrm{C}$ showing good correlation with the equilibrium Thermo-Calc results in Figure 2.

The temperature within the molten weld pool was recorded via tungsten-rhenium Type $\mathrm{C}$ thermocouples during welding. Figure 4 combines the results of weld pool temperature recordings with a processed 
Equilibrium Conditions

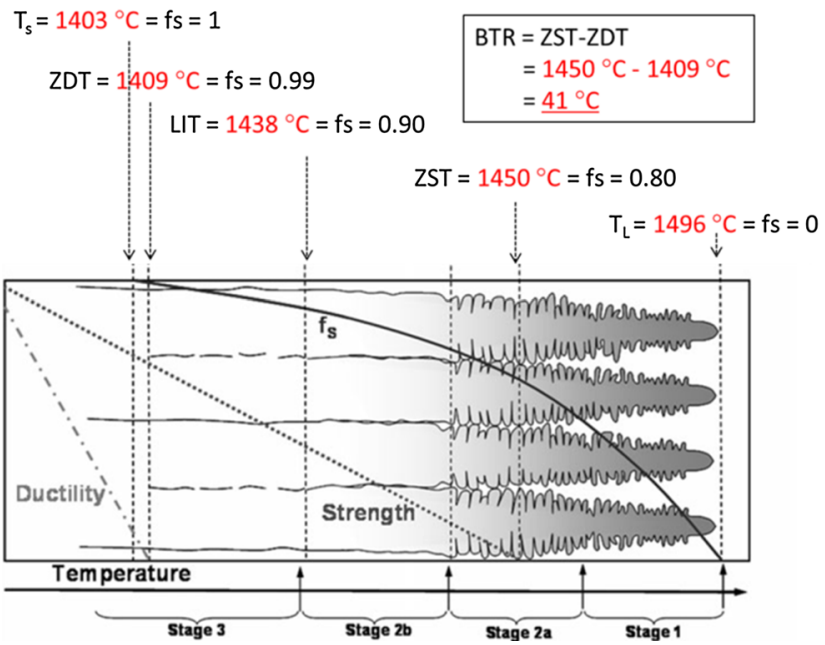

Scheil Conditions

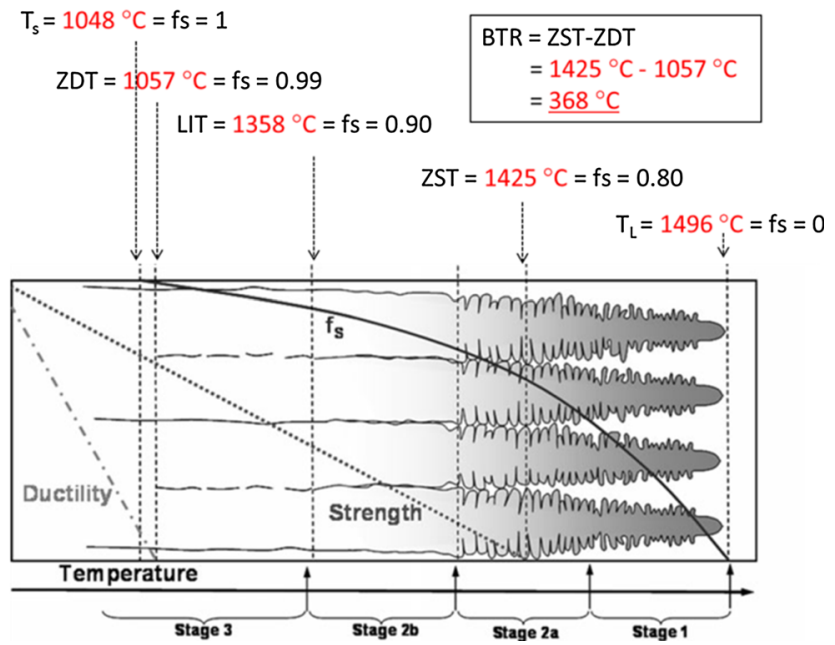

Fig. 2-Schematic illustration of solidification stages relating to solidification cracking adapted from Ref. [39] by including values calculated from the results of EN1A alloy Thermo-Calc simulations under equilibrium and non-equilibrium (Scheil) conditions.

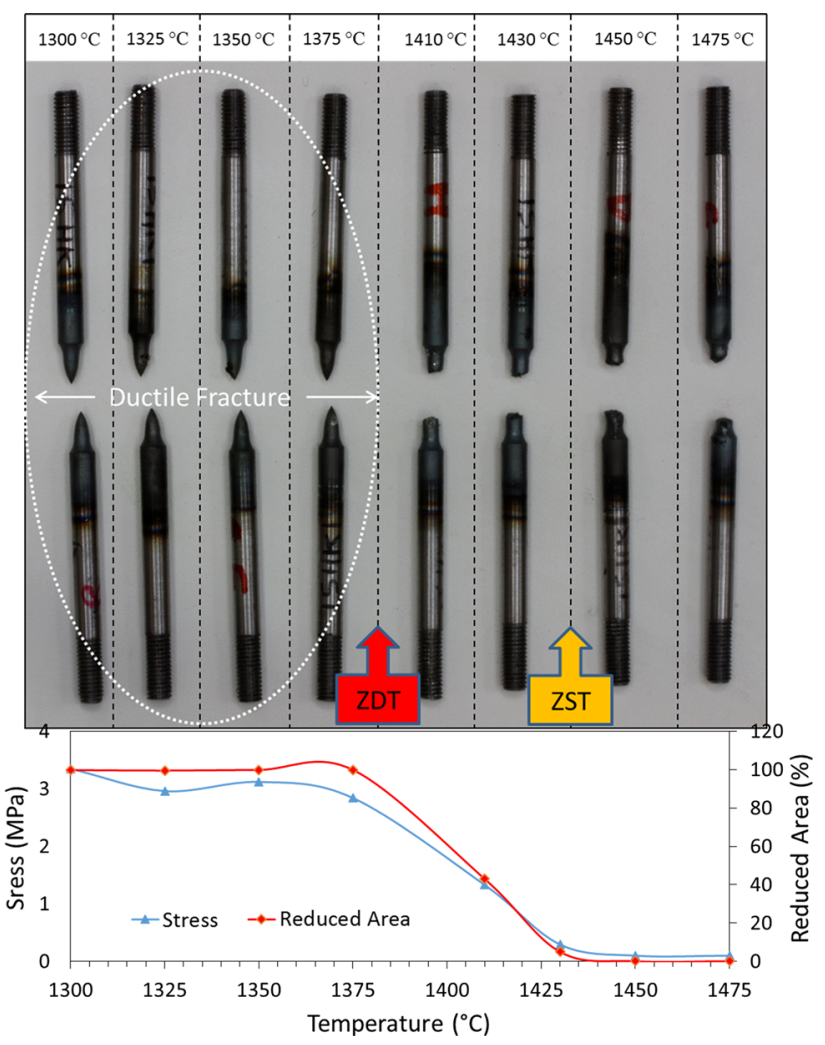

Fig. 3-Results of Gleeble hot ductility tests. Samples tested at lower temperatures show good elongation and ductility prior to fracture. The ZDT is between $1375{ }^{\circ} \mathrm{C}$ and $1410{ }^{\circ} \mathrm{C}$ and the ZST between $1430{ }^{\circ} \mathrm{C}$ and $1450{ }^{\circ} \mathrm{C}$.

radiograph which identifies the damage initiation site. The distance $(2.69 \mathrm{~mm})$, between the heat source and where solidification cracking was observed, was used to extrapolate an approximate crack initiation temperature from the measured temperature curve. A value of $1433{ }^{\circ} \mathrm{C}$ is extrapolated from Figure 4 for crack initiation temperature. The solid fraction from Thermo-Calc (equilibrium, Figure 2) and hot ductility data (Figure 3) at $1433{ }^{\circ} \mathrm{C}$ is 0.92 .

Cracks initiate at the terminal stage of solidification $^{[39]}$ when small amounts ( $\sim 0.08$ volume fraction) of liquid remain. Hot cracks typically develop in thin inter-granular liquid pockets after the solidification morphology transforms to grain structure from dendrites. The pockets form at grain boundaries due to segregated elements in the liquid with a low melting point. Solid-state creep is the main way to accommodate solidification shrinkage and thermal stresses at this stage.

\section{B. Crack Nucleation}

Figure 4 suggests that solidification cracking initiates at $1433{ }^{\circ} \mathrm{C}$. At this temperature, inter-granular hot cracking is expected, if thermodynamic conditions identified in equilibrium Thermo-Calc simulations and Gleeble tests are assumed. To ascertain this, fracture initiation sites were analyzed using computer tomography and SEM.

Figure 5(a) is a 3D tomographic reconstruction of crack initiation sites as identified in Figure 4. Figure 5(b) shows the as-solidified faceted ferritic grain structure observed on the fracture surface of the corresponding test piece. Figure 5(c) reveals that the fracture is inter-granular and brittle with a high volume of porosity inherent to the facets. The fracture can be classified as stage 3 hot cracking; only the grains are observed and no dendrite morphology is present on the fracture surface.

Figure 5(d) shows two segregation-related features where fracture nucleates:

1. The orange circles highlight two MnS particles. The MnS particles are type III sulfides ${ }^{[40]}$ which appear as idiomorphic crystals scattered through the whole 


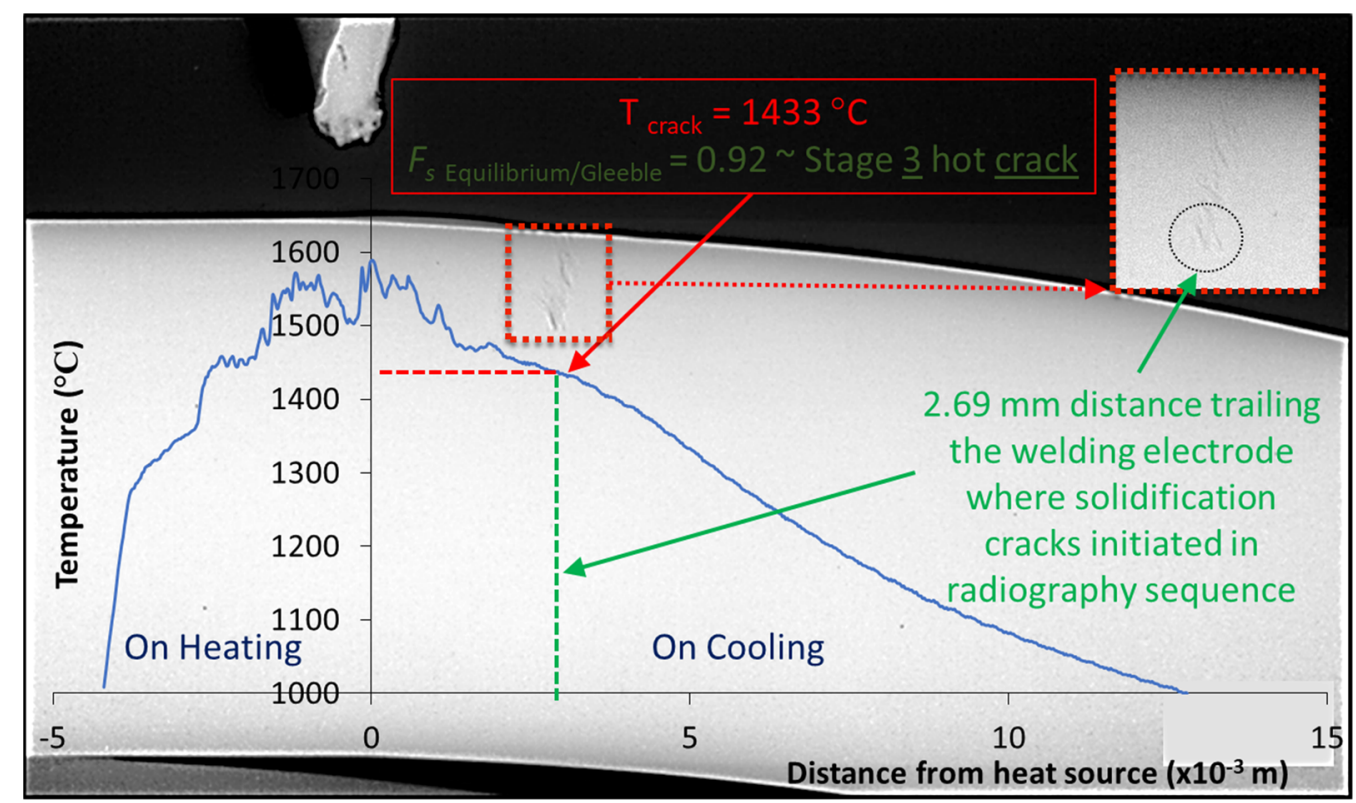

Fig. 4-Synchrotron X-ray radiograph showing crack nucleation sites. Measured temperature in the molten weld pool during testing is superimposed onto the radiograph. Crack nucleation temperature is extrapolated and related to solid fraction.

dendritic structure but frequently are situated in inter-dendritic spaces. $\mathrm{MnS}$ is a low melting eutectic with a much lower solidification point than the bulk metal. As a result, MnS will remain in its liquid phase after the bulk has solidified and form a liquid interface at grain boundaries of the solid bulk metal.

2. The broken red circle displays the presence of globular particles more numerous in population. The particles are inherent to the grain boundaries of the fracture surface and enriched in solute elements $\mathrm{Mn}, \mathrm{Al}$, and in particular, Si. The size (approximately between 5 and $20 \mu \mathrm{m}$ ) and globular morphology of the particles correlate well with the size and shape of the fracture initiating cavities that are presented in Figure 5(a).

The fractures observed in Figure 5 support the argument that solidification cracking during welding initiates as stage 3 hot cracking in the final stages of solidification after the dendrite to grain transition when the volume fraction of liquid is $<0.1$. It appears that the hot cracks nucleate inter-granularly at pockets of eutectic liquid segregated at the grain boundaries.

\section{Crack Propagation}

1. Propagation via coalescence of nucleated inter-granular hot cracks

In practice, alloys with high fractions of liquid in the vulnerable solidification range are not susceptible to solidification cracking. ${ }^{[2,41]}$ Cavities and gaps between grains that may form in the mushy zone of such alloys due to solidification shrinkage, presence of non-wetted inclusions, thermal contraction, or external tension are easily filled with liquid due to the adequate permeability of the mushy zone and sufficient amount of available liquid that is represented in the final structure by non-equilibrium eutectics. ${ }^{[41]}$ Much more important is the mechanism of solidification crack propagation when there is little residual liquid remaining. Information on semi-solid fracture in such cases is rare. To summarize the findings available to date, it would appear that bridging of grain boundaries is an essential feature of the fracture surface. ${ }^{[31]}$ Moreover, the closer the semisolid material gets to the temperature range of its maximum vulnerability to hot cracking, i.e., 0.9 to 0.95 fraction solid, the greater the fraction of grain boundaries connected to each other, or coalesced. ${ }^{[42]}$

In Section III-B, solidification cracking is found to nucleate as inter-granular hot cracks when the volume fraction of liquid is $<0.1$. Tomography analysis in Figure 6(a) suggests that in the initial stage crack propagation is driven via the coalescence of crack cavities. In this stage, there is no chance for the crack propagation through a continuous liquid film as such a film does not exist. Eskin ${ }^{[43]}$ shows that a solidification crack propagates through the liquid film in more alloyed materials and through solid bridges in less alloyed materials. SEM examination of the fracture surfaces in Figures 6(b) and (c) reveals complex fracture surfaces. Islands of inter-granular fracture are located on inter-dendritic fracture regions. Examination of Figure 6(c) reveals that the islands appear to have coalesced during the fracture process and propagated into the inter-dendritic region.

\section{Propagation via hot tearing}

Most of the reports on solidification cracking describe the failure of semi-solid alloys at relatively large fractions of liquid (hot tearing), when grain boundaries are completely covered with liquid. ${ }^{[10,19-21]}$ The 

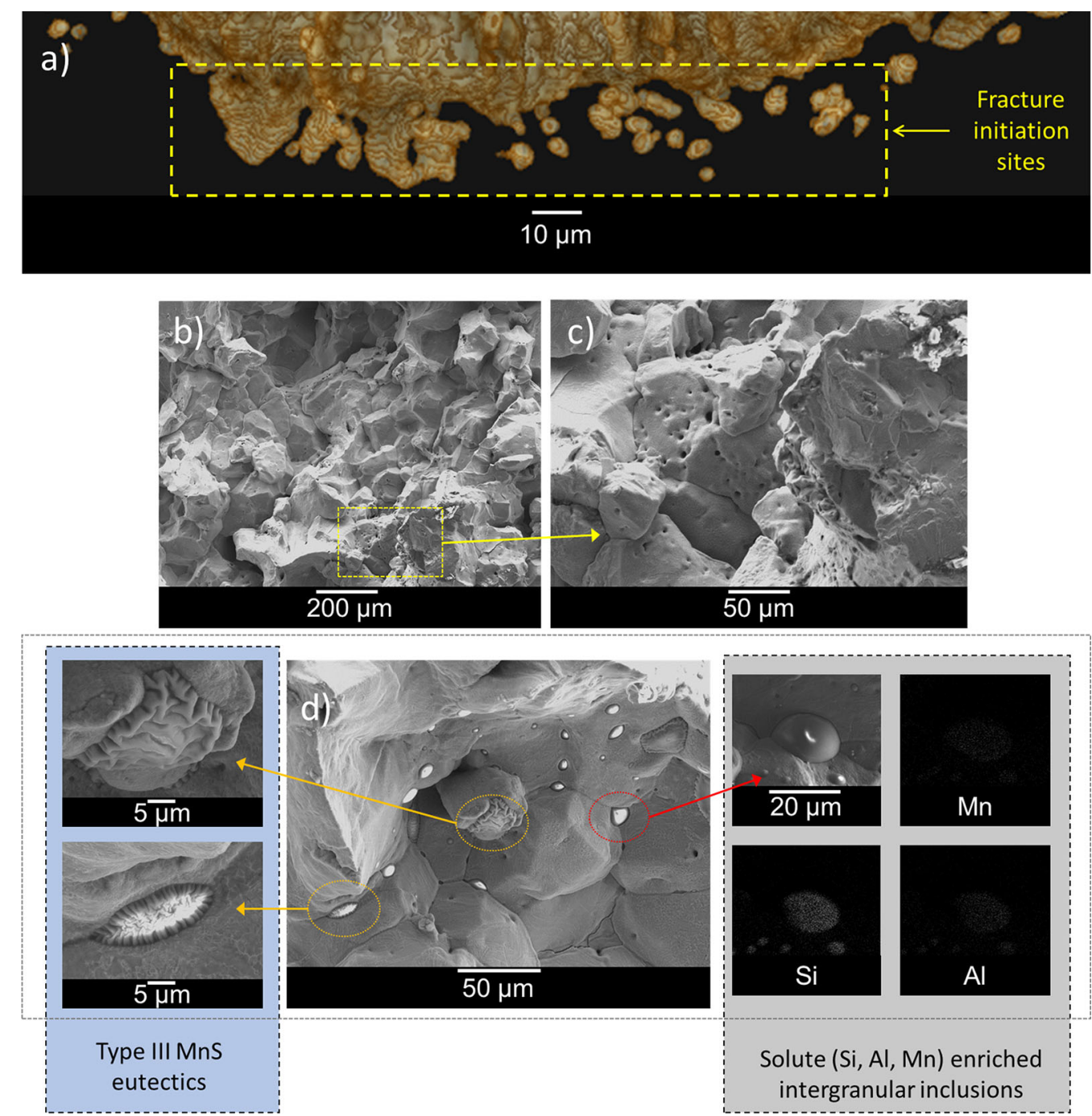

Fig. 5-Images of fracture initiation sites showing (a) tomography image of fracture initiation sites identified in Fig. 4, (b) SEM image of the fracture surfaces in as-solidified faceted ferritic grains, the facets result from brittle inter-granular fracture, $(c)$ magnified SEM image of the porosity inherent to the faceted grains, $(d)$ SEM image of solute-enriched grain boundary eutectics inherent to the fracture surface. The orange broken circles highlight two low melting point Type III MnS particles while the broken red circle highlights the presence of numerous globular particles enriched in solute elements ( $\mathrm{Si}$ in particular) inherent to grain boundaries.

mechanism of crack propagation in the case of hot tearing - through liquid film by dendrite arm separation - is obvious. An example of this type of fracture is observed in Figure 7 which displays the fracture surface on the bulk crack, away from the site of fracture nucleation. The fracture observed in Figure 7 is inter-dendritic and categorized as stage 2 hot tearing. Stage 2 hot tears occur at higher volume fractions of liquid prior to the dendrite to grain transformation, in comparison to the stage 3 hot cracks which occur after the dendrite to grain transformation.

Crack grows at a fairly even rate inwards, towards the weld center and sample free surface. The kinetics of damage growth towards the free -surface from the sample core is in agreement with similar studies on binary $\mathrm{Al}-\mathrm{Cu},{ }^{[19,44]}$ ternary $\mathrm{Al}-\mathrm{Si}-\mathrm{Cu},{ }^{[17]}$ and other commercial alloys. ${ }^{[21]}$

\section{A Three-Stage Mechanistic Model for Solidification Cracking During Welding of Steel}

From the results presented in this study, a three-stage mechanistic model for solidification cracking during welding of steel is proposed. Three distinct stages for solidification cracking are illustrated in Figure 8.

1. Stage 1: nucleation of inter-granular hot cracks

During weld pool solidification, after the transition from the dendrite to the grain structure when the volume fraction of liquid is $<0.1$ and temperature is approaches solidus $1703 \mathrm{~K}\left(\sim 1430{ }^{\circ} \mathrm{C}\right)$, solute elements $(\mathrm{Mn}, \mathrm{Si}, \mathrm{Al})$ and impurities (S) segregate to grain boundaries. As a result, liquid pockets with eutectic chemistries form at the inter-granular regions. Under a nominal tensile strain of $\sim 3.25$ pct, hot cracks form sub-surface at the inter-granular sites where pockets of 

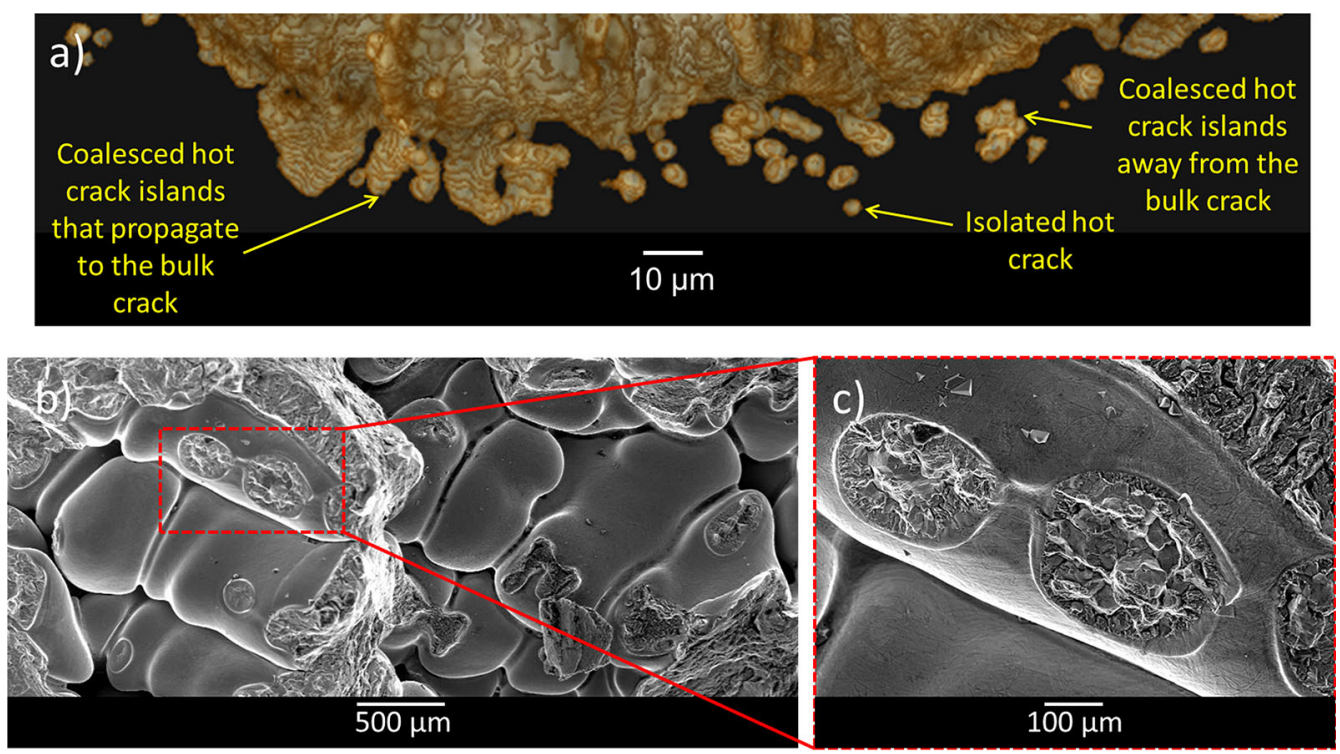

Fig. 6-Images of initial damage propagation stages: (a) a tomography image of hot crack distribution illustrating isolated cavities, coalescence islands away from the bulk crack, and also islands that propagate to the bulk crack, $(b)$ an SEM image of dendritic fracture observed on the corresponding sample. The dendrites have islands of inter-granular fracture located upon them, $(c)$ closer examination of the inter-granular islands showing signs of coalescence between islands and into the inter-dendritic structure.
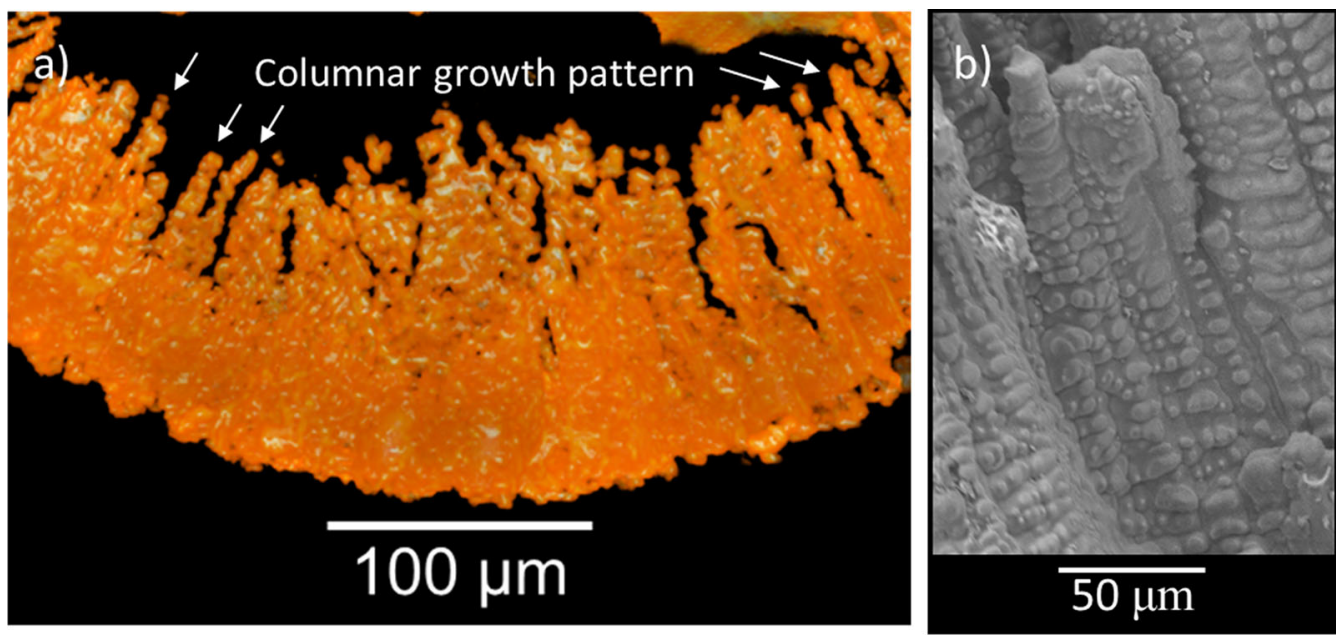

Fig. 7-Images of bulk fracture surfaces: $(a)$ a tomographic image of columnar crack growth path, $(b)$ an SEM image of columnar dendritic fracture morphology observed on the bulk fracture surface showing inter-dendritic fracture associated with stage 2 hot tearing.

residual eutectic liquid are concentrated, as illustrated in Figure 8 and evidenced in Figure 5. Traditionally a crack would initiate at the weakest point. The theory proposed in this study suggests the opposite i.e., that cracks initiate in the latest stages of solidification when the ductility and strength are already building up. Cracks will also initiate, constantly, prior to this, when liquid fraction is higher and strength and ductility are zero. However, as the liquid fraction is high in this instance, the solid skeleton is highly permeable, and any crack openings are immediately filled with inter-dendritic liquid. As solidification proceeds, and the liquid fraction becomes very low, the permeability of the solid is vastly reduced. In this case, any opening of a crack cannot be filled by the remaining liquid. As a result, the first permanent cracks (pockets of air not filled by liquid) only begin to appear in the terminal stages, when the material has some ductility and strength, but low permeability and liquid feeding.

\section{Stage 2: coalescence of hot cracks by inter-granular} fracture

As the strain increases, the hot cracks then coalesce inter-granularly through the fracture. Some cracks do not coalesce so the cracks remain isolated; meanwhile other cracks do coalesce with each other but remain isolated from the bulk crack, as evidenced in Figure 6. Eventually the coalescence of cracks propagates through the grain structure to the solidifying dendritic structure, as illustrated in Figure 8. 


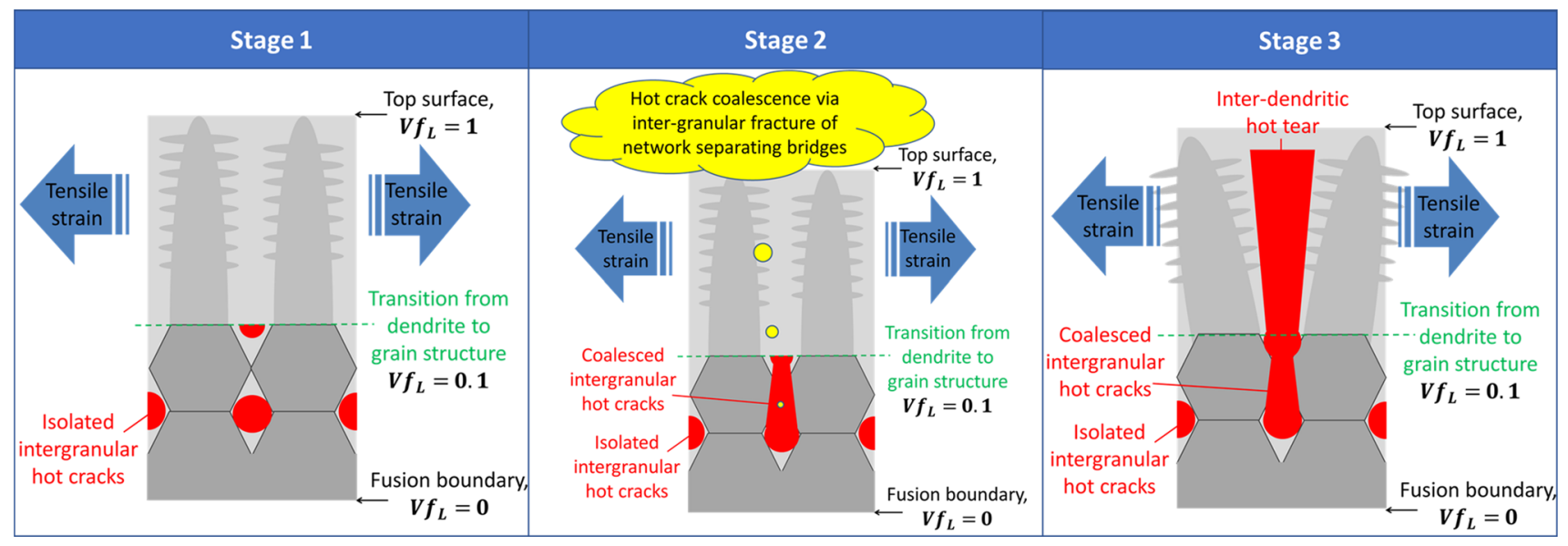

Fig. 8-2D schematic illustration of solidification cracking mechanisms. At stage 1, inter-granular hot cracks nucleate upon low melting point phases after the transition from the dendrite to the grain structure. At stage 2, hot cracks begin to coalesce via inter-granular fracture. Some cracks remain isolated and some coalesce with each other. The coalescence of the hot cracks eventually propagates through the grain structure to the solidifying dendrites. At stage 3, inter-dendritic hot tearing becomes the dominant propagation mechanism.

\section{Stage 3: propagation by hot tearing}

Once the coalescence of the inter-granular hot cracks has propagated through to the solidifying dendrites, hot tearing begins. At this stage, the volume fraction of liquid is higher and inter-dendritic fracture is observed from the separation of primary dendrite arms as a result of tensile deformation as shown in Figure 8 and evidenced in Figure 7. As the propagation is linked to the solidifying dendrites, the propagation path is related to that of the growing dendrites in terms of direction (towards the heat source) and in a velocity of $\sim 2.3 \mathrm{~mm} /$ $\mathrm{s}^{[36]}$. Strain is the driving force for crack propagation and continues to develop with solidification. If solidification and strain continued indefinitely, cracks would continue to propagate, via the mechanisms proposed, indefinitely. The rate of solidification and strain will affect the rate of crack propagation. If the driving force (strain) is removed completely, then cracks would lose the force driving propagation and growth. In such an instance, it is proposed that a certain amount of the crack, likely the advancing crack tip, where higher liquid fraction is present, would be filled with eutectic inter-dendritic liquid. As solidification proceeds, the eutectic liquid would eventually solidify to heal at least a portion of the crack.

\section{CONCLUDING REMARKS}

In a previous study, an in situ synchrotron X-ray imaging experiment ${ }^{[36]}$ was presented to observe and quantify the initiation and growth kinetics of solidification cracking during welding of steel. In this study, the mechanisms for solidification cracking are elaborated by identifying the thermodynamic state and localized structure features at both nucleation sites and the resultant fracture surfaces. A three-stage mechanistic model for solidification cracking during welding of steel is proposed:

Stage 1 Nucleation of inter-granular hot cracks: cracks nucleate inter-granularly in sub-surface where maximum volumetric strain is localized and volume fraction of liquid is less than 0.1 ; the crack nuclei occur at solute-enriched liquid pockets which remain trapped in increasingly impermeable skeletons.

Stage 2 Coalescence of cracks via inter-granular fracture: as the applied strain increases, cracks coalesce through inter-granular fracture; the coalescence path is preferential to the direction of the heat source and propagates through the grain boundaries to solidifying dendrites.

Stage 3 Propagation through inter-dendritic hot tearing: inter-dendritic hot tearing occurs along the boundaries between solidifying columnar dendrites with higher liquid fraction.

The above model can provide an insight into the nucleation and propagation mechanisms for solidification cracking during high-solidification-rate processing of steel. Future solidification cracking criterion shall be based on the application of multiphase mechanics and fracture mechanics to the failure of semi-solid materials during welding of steel.

\section{ACKNOWLEDGMENTS}

This work was funded by an ESPRC PhD case award to L. Aucott and was also supported by the European Commission as a part of the FP7 programme, Modelling of Interface Evolution in Advanced Welding; Contract No. NMP3-SL-2009-229108. Dr S.W. Wen is currently with Dongguan Centre of Excellence for Advanced Materials, Dongguan, Guangdong, China.

\section{REFERENCES}

1. G.K. Sigworth: AFS Trans., 1996, vol. 104, pp. 1053-62.

2. D.G. Eskin and L.Katgerman. Suyitno: Prog. Mater. Sci., 2004, vol. 49 (5), pp. 629-711.

3. W.S. Pellini: Foundry, 1952, vol. 80, pp. 125-33.

4. W.I. Humphrey: J. Inst. Metals, 1948, vol. 75, p. 235. 
5. J.C. Borland: Br. Weld. J., 1960, vol. 7, pp. 508-12.

6. U. Feurer: Giessereiforschung, 1976, vol. 28 (2), pp. 75-80.

7. Y.F. Guven and J.D. Hunt: Cast Met., 1988, vol. 1 (2), pp. 104-11.

8. M. Rappaz, J.M. Drezet, and M. Gremaud: Metal. Mater. Trans. A, 1999, vol. 30A (2), pp. 449-55.

9. J. Campbell: Castings, Butterworth-Heinemann, Oxford, United Kingdom, 2003.

10. S. Kou: Acta Mater., 2015, vol. 88, pp. 366-74.

11. I. Farup, J.M. Drezet, and M. Rappaz: Acta Mater., 2001, vol. 49 (7), pp. 1261-69.

12. P.D. Grasso, J.M. Drezet, and M. Rappaz, J. Metal. - electronic edition, 2002.

13. J. Aveson, IOP Conf. Series: Mater. Sci. Eng., 2012, p. 33.

14. C. Davidson, D. Viano, L. Lu, D. St.John, and C. Davidson: Int. J. Cast Metal. Res., 2006, vol. 19 (1), pp. 59-65.

15. C. Puncreobutr, A.B. Phillion, J.L. Fife, P. Rockett, A.P. Horsfield, and P.D. Lee: Acta Mater., 2014, vol. 79, pp. 292-303.

16. C. Puncreobutr, A.B. Phillion, J.L. Fife, and P.D. Lee: Acta Mater., 2014, vol. 64, pp. 316-25.

17. C. Puncreobutr, P.D. Lee, K.M. Kareh, T. Connolley, J.L. Fife, and A.B. Phillion: Acta Mater., 2014, vol. 68, pp. 42-51.

18. M. Sistaninia, S. Terzi, A.B. Phillion, J.M. Drezet, and M. Rappaz: Acta Mater., 2013, vol. 61 (10), pp. 3831-41.

19. A.B. Phillion, R.W. Hamilton, D. Fuloria, A.C.L. Leung, P. Rockett, T. Connolley, and P.D. Lee: Acta Mater., 2011, vol. 59 (4), pp. 1436-44.

20. A.B. Phillion, P.D. Lee, E. Maire, and S.L. Cockcroft: Mater. Trans. A, 2008, vol. 39A (10), pp. 2459-69.

21. A.B. Phillion, S.L. Cockcroft, and P.D. Lee: Mater. Sci. Eng. A, 2008, vol. 491 (1-2), pp. 237-47.

22. A.B. Phillion, S.L. Cockcroft, and P.D. Lee: Scripta Mater., 2006, vol. 55 (5), pp. 489-92.

23. W.M. Van Haaften, W.H. Kool, and L. Katgerman: J. Mater. Eng. Perform., 2002, vol. 11 (5), pp. 537-43.

24. P.J.G. Harris, Alum. Alloy. 2002 - ICAA8 2002, pp. 179-84.

25. M. Sistaninia, A.B. Phillion, J.M. Drezet, and M. Rappaz: Acta Mater., 2012, vol. 60 (19), pp. 6793-6803.

26. C.M. Gourlay, A.K. Dahle, T. Nagira, N. Nakatsuka, K. Nogita, K. Uesugi, and H. Yasuda: Acta Mater., 2011, vol. 59 (12), pp. 4933-43.
27. M. Rappaz, P.-D. Grasso, V. Mathier, J. Drezet, and A. Jacot: TMS, PA, Warrendale, 2005, pp. 179-90.

28. K.M. Kareh, C. O’Sullivan, T. Nagira, H. Yasuda, and C.M. Gourlay: Acta Mater., 2017, vol. 125, pp. 187-95.

29. B. Cai, S. Karagadde, L. Yuan, T.J. Marrow, T. Connolley, and P.D. Lee: Acta Mater., 2014, vol. 76, pp. 371-80.

30. C.M. Gourlay and A. Dahle: Nature, 2007, vol. 445 (7123), pp. 70-73.

31. D.G. Eskin and L. Katgerman: Metal. Mater. Trans. A, 2007, vol. 38A (7), pp. 1511-19.

32. M. Tong, G. Duggan, J. Liu, Y. Xie, M. Dodge, L. Aucott, H. Dong, J. Dantzig, O. Barrera, A.F. Cocks, H. Kitaguchi, S. Lozano-Perez, C. Kleijn, and S. Wen: JOM, 2013, vol. 65 (1), pp. 99-106.

33. L. Aucott, S.W. Wen, A. Sullivan, H.B. Dong, 4th Int. Integr. High Temp. Weld. Conf., London, 2012.

34. L. Aucott: Mechanism of Solidification Cracking During Welding of High Strength Steels for Subsea Linepipe. PhD Thesis, Univeristy of Leicester, Department of Engineering, 2015.

35. L. Aucott, S.W. Wen, and H. Dong: Mater. Sci. Eng: A, 2015, vol. 622, pp. 194-203.

36. L. Aucott, D. Huang, H.B. Dong, S.W. Wen, J.A. Marsden, A. Rack, and A.C.F. Cocks: Sci. Rep., 2017, vol. 7, p. 40255.

37. P. Cloetens, J. Baruchel, J.-P. Guigay, and M. Schlenker: J. Phys. D: Appl. Phys., 1996, vol. 29 (1), pp. 133-46.

38. C.A. Schneider, W.S. Rasband, and K.W. Eliceiri: Nat. Meth., 2012, vol. 9 (7), pp. 671-75.

39. B. Santillana, R. Boom, D. Eskin, H. Mizukami, M. Hanao, and M. Kawamoto: Metal. Mater. Trans. A, 2012, vol. 43A (13), pp. $5048-57$.

40. L.K. Bigelow and M.C. Flemings: Metal Trans. B, 1975, vol. 6 (2), pp. $275-83$.

41. V.I. Savran, L. Katgerman, and D.G. Eskin: Metall. Mater. Trans. A, 2004, vol. 35A (11), pp. 3551-61.

42. Y. Ju: Ph.D. Thesis, Norwegian University of Science and Technology, Trondheim, Norway, 2004.

43. D. Eskin, Suyitno, and L. Katgerman: Proc. 9th Australasian Conf., CSIRO Publishing, Collingwood, 2005, pp. 77-84.

44. S. Terzi: Scripta Mater., 2009, vol. 61, pp. 449-52. 